\title{
Neuromyelitis optica (Devic's syndrome): no association with the primary mitochondrial DNA mutations found in Leber hereditary optic neuropathy
}

\author{
H Cock, R Mandler, W Ahmed, A H V Schapira
}

\begin{abstract}
Devic's neuromyelitis optica is a rare syndrome characterised by the combination of acute or subacute optic neuritis and transverse myelitis, in some cases considered to be a variant of multiple sclerosis. Mutations of mitochondrial DNA (mtDNA) associated with Leber hereditary optic neuropathy (LHON) have been identified in some patients with multiple sclerosis in whom optic neuritis is a prominent early feature. Using restriction enzyme digestion of mtDNA products amplified by the polymerase chain reaction, the primary LHON mtDNA mutations at positions $3460 \mathrm{bp}$, 11778 bp, and 14484 bp have been excluded in four women with Devic's neuromyelitis optica. A mutation at 4160 bp associated in some LHON families with more widespread neurological disease was also not detected. It is concluded that the primary mtDNA mutations currently associated with LHON are not responsible for the prominence of optic nerve disease in Devic's neuromyelitis optica.
\end{abstract}

\section{$(\mathcal{F}$ Neurol Neurosurg Psychiatry 1997;62:85-87)}

Department of Clinical Free Hospital School of Medicine, London, UK

A H V Schapira

Department of Neurology, University of New Mexico,

Alberquerque, USA

$R$ Mandler

W Ahmed

University Department of Clinical Neurology,

Institute of Neurology,

London, UK

A H V Schapira

Correspondence to:

Professor A H V Shapira

Department of Clinical

Neurosciences, Royal Free

Hospital School of Medicine,

Rowland Hill Street, London

NW3 2PF, UK.

Received 10 July 1996

and in revised form

19 September 1996

Accepted 20 September 1996
Keywords: Devic's neuromyelitis optica; Leber hereditary optic neuropathy; mitochondrial DNA; multiple sclerosis

Devic's neuromyelitis optica is a syndrome characterised by acute or subacute optic neuritis and transverse myelitis. ${ }^{1}$ In most patients there is no known specific aetiology. Devic's neuromyelitis optica is considered by some,${ }^{23}$ but not others, ${ }^{4}$ to be a variant of multiple sclerosis. The reasons for the particular susceptibility of the optic nerves and spinal cord in these patients is not known. Leber hereditary optic neuropathy (LHON) is the commonest cause of isolated blindness in otherwise healthy young men, and is characterised by a subacute sequential painless visual loss clinically similar to that seen in Devic's syndrome. ${ }^{5}$ In most cases LHON is a familial condition displaying strict maternal inheritance, although sporadic cases also occur. Over $90 \%$ of all patients with LHON harbour one of three point mutations of mitochondrial DNA (mtDNA): these "primary" mutations, at positions $3460 \mathrm{bp}, 11778 \mathrm{bp}$, and $14484 \mathrm{bp}$, have only been documented in families with LHON and not in control populations, and involve moderate or highly conserved amino acids in evolutionarily constrained polpypeptide domains. ${ }^{6}$ LHON has also been reported in association with a multiple sclerosis-like illness ${ }^{7} 8$ especially in women. A further report showed the occurrence of LHON mtDNA mutations in a few patients with multiple sclerosis with no family history of LHON, but in whom optic neuritis was a prominent early symptom. ${ }^{9}$ Despite the prominence of optic nerve symptoms, studies of $\mathrm{mtDNA}$ in Devic's syndrome have not been reported.

We have looked for the three primary mtDNA mutations associated with LHON in four unrelated patients with a clinical diagnosis of Devic's syndrome. We also looked for a mutation at $4160 \mathrm{bp}$ which has been seen in families with LHON in association with more widespread neurological disease. ${ }^{10}$ All the patients with Devic's syndrome had an acute myelitis followed by unilateral or bilateral optic neuritis within six months. There was no evidence of maternally inherited disease in the families of any of the patients. Brain MRI and routine blood tests were normal in all cases. The table gives clinical details and the results of preliminary investigations.

\section{Methods}

Analysis of mtDNA was carried out on cell lysates prepared from whole blood samples from each patient as follows: one plate of washed harvested cells was washed three times in $600 \mu \mathrm{l}$ buffer containing $10 \mathrm{mM}$ Tris $\mathrm{Cl}$ (pH 8.0) and $1 \mathrm{mM}$ EDTA, with pelleting by centrifugation at $15000 \mathrm{~g}$ for five minutes. The final pellet was incubated for 20 minutes at $55^{\circ} \mathrm{C}$ with $80 \mu \mathrm{g}$ proteinase $\mathrm{K}$ in $200 \mu \mathrm{l}$ of cell lysis buffer (20 mM Tris $\mathrm{Cl}(\mathrm{pH} 8.3)$, $50 \mathrm{mM} \mathrm{KCl}, 2.5 \mathrm{mM} \mathrm{MgCl}_{2}, 0.45 \%$ (v/v) Tween 20 , and $0.45 \%(\mathrm{v} / \mathrm{v})$ Nonidet $\mathrm{p} 40)$. A final incubation at $90^{\circ} \mathrm{C}$ for 10 minutes with the addition of $100 \mu \mathrm{l}$ water was undertaken before storage of the lysate at $-20^{\circ} \mathrm{C}$.

The presence or absence of the mtDNA 
Clinical details of patients with Devic's syndrome

\begin{tabular}{|c|c|c|c|c|c|c|}
\hline \multirow[b]{2}{*}{ Patient } & \multirow{2}{*}{$\begin{array}{l}\text { Onset } \\
\text { age/sex }\end{array}$} & \multicolumn{2}{|c|}{ Clinical features } & \multirow[b]{2}{*}{ MRI abnormalities } & \multicolumn{2}{|l|}{ CSF findings } \\
\hline & & Myelitis & Optic neuritis (delay ${ }^{\star}$ ) & & protein $(g / l)$ & IgG/oligoclonals \\
\hline 1 & $41 / \mathrm{F}$ & Thoracic & Left ( 3 months) & $\begin{array}{l}\text { High signal cavitating } \\
\text { swelling in thoracic cord }\end{array}$ & 0.59 & - ve \\
\hline 2 & $73 / \mathrm{F}$ & Cervical & Bilateral (4 months) & $\begin{array}{l}\text { High signal cavitating } \\
\text { swelling in cervical and } \\
\text { thoracic cord }\end{array}$ & $0 \cdot 64$ & - ve \\
\hline 3 & $64 / F$ & Thoracic & Left (6 months) & $\begin{array}{l}\text { Lower cervical and } \\
\text { thoracic cord swelling }\end{array}$ & $0 \cdot 89$ & -ve \\
\hline 4 & $34 / F$ & Thoracic & Bilateral (simultaneous) & $\begin{array}{l}\text { Swollen cervical cord } \\
\text { with cavitation }\end{array}$ & $0 \cdot 60$ & - ve \\
\hline
\end{tabular}

^Delay represents the maximum time between the onset of spinal cord and optic symptoms.

mutations associated with LHON was determined by restriction enzyme digestion of polymerase chain reaction (PCR) amplified mtDNA fragments, separated on ethidium bromide stained agarose gels. The G11778A ND4 mutation causes a loss of a restriction site with Mae III ${ }^{11}$ and the G3460A ND1 mutation a loss of a Hinl 1 restriction site. ${ }^{12}$ An Mbo 1 restriction site was generated with mismatch primers replacing a cytosine with guanine at position 14482 . The T14 484C ND6 mutation results in a loss of this site. The T4160C ND1 mutation results in a loss of a BstX 1 restriction site generated by mismatch primers replacing $T$ with $C$ at positions 4200 and 4201. mtDNA amplified by PCR from patients positive for each of the mutations, and from controls was analysed in parallel to samples from each of the four patients with Devic's syndrome. Restricted PCR products were then separated and visualised on agarose gels stained with ethidium bromide.

\section{Results}

None of the three primary LHON mtDNA mutations, or that at position 4160 , were detected in any the patients with Devic's syndrome (data not shown). In all cases complete digestion of the PCR products in controls and patients with Devic's disease was seen. The loss of restriction site as a result of the mtDNA mutations was confirmed in patients with LHON known to be positive for each of the mutations studied.

\section{Discussion}

The pathogenesis of Devic's syndrome is not understood, and the question of whether or not Devic's syndrome represents a variant of multiple sclerosis has not been completely resolved. We have suggested that Devic's syndrome may be distinct from multiple sclerosis in that the brain MRI is normal and CNS IgG synthesis or oligoclonal bands in the CNS are uncommon, ${ }^{4}$ findings supported by other groups. ${ }^{1315}$ Pathological changes in the largest series of clinically typical cases of Devic's syndrome ${ }^{4}$ included white matter plaques in the optic nerves, but not in the brain, brainstem, or cerebellum. The most striking pathological defect was necrosis of both grey and white matter in the spinal cord. Others have reported extensive demyelination with vascular infiltrates, ${ }^{16}$ or cystic degeneration of the spinal cord and optic chiasm. ${ }^{17}$ By contrast some authors have considered Devic's syndrome and multiple sclerosis to be part of the same spectrum, reporting widespread cortical and brainstem lesions identical to those seen in multiple sclerosis on $\mathrm{MRI},{ }^{23}$ some response to steroids, ${ }^{18}$ and pathological evidence of optic nerve and spinal cord demyelination in subjects with clinically typical Devic's syndrome. ${ }^{13}$ Thus Devic's syndrome may, to some extent, represent a clinically and pathologically defined entity resulting from various aetiological mechanisms.

Given the associations between LHON mtDNA mutations and optic neuritis in some patients with multiple sclerosis previously discussed, ${ }^{9}$ we considered that LHON mtDNA mutations might also contribute to the vulnerability of the optic nerve in Devic's syndrome. None of the primary LHON mtDNA mutations were detected in the blood of four women with clinically typical Devic's syndrome. The 4160 bp mutation which has been reported in a Queensland family with hereditary optic neuropathy and more widespread CNS disease was also not detected. Although other tissues were not studied, molecular genetic diagnosis of mitochondrial mutations from blood samples is a well established technique, ${ }^{19}$ and has been widely used in studies of LHON. ${ }^{6}$ Many other mtDNA mutations have been associated with LHON. ${ }^{20}$ Our study did not exclude any of these "secondary mutations", but their pathogenetic relevance is disputed as they are also found at low frequency in control populations. ${ }^{21}$ This study does not support the contention that the mtDNA mutations associated with LHON might contribute to the vulnerability of the optic nerve in Devic's syndrome. Further studies on more patients would extend this data, but as with multiple sclerosis it is likely that in most patients with Devic's syndrome LHON mtDNA mutations do not play a part in pathogenesis of disease. ${ }^{22}$

This work has been supported by a Medical Research Council training fellowship to HRC.

1 Whitham RH, Brey RL. Neuromyelitis optica: two new cases and review of the literature. 7 Clin NeuroOphthalmol 1985;5:263-9.

2 Igarashi $Y$, Oyachi $H$, Nakamura $Y$, Hashimoto $M$, Ohwada Y, Mito Y. Neuromyelitis optica. Ophthalmologica 1994;208:226-9.

3 Amold TW, Myers GJ. Neuromyelitis optica (Devic syndrome) in a 12-ys G. Neuro with complete recovery foldrome) in a 12-year-old male with complete

4 Mandler RM, Davis LE, Jeffrey DR, Konfeld M. Devic's neuromyelitis optica: a clinicopathological study of 8 patients. Ann Neurol 1993;34:162-8. 
5 Riordan-Eva P, Sanders M, Govan GG, Sweeney MG, Da Costa J, Harding AE. The clinical features of Leber's hereditary optic neuropathy defined by the presence of hereditary optic neuropathy defined by the presence of a pathogenic mit

6 Riordan-Eva P, Harding AE. Leber's hereditary optic neuropathy: the clinical relevance of different mitochondria DNA mutations. F Med Genet 1995;32:81-7.

7 Flanigan KM, Johns DR. Association of the 11778 mitochondrial DNA mutation and demyelinating disease. Neurology 1993;43:2720-1.

8 Harding AE, Sweeney MG, Miller DH, et al. Occurrence of a multiple sclerosis-like illness in women who have a Leber's hereditary optic neuropathy mitochondrial DNA mutation. Brain 1992;115:979-89.

9 Kellar-Wood H, Robertson N, Govan GG, Compston DAS, Harding AE. Leber's hereditary optic neuropathy mitochondrial DNA mutations in multiple sclerosis. Ann mitochondrial DNA mutat

10 Howell N, Kubacka I, Xu M, McCullough DA. Leber hereditary optic neuropathy: involvement of the mitochondrial ND1 gene and evidence for an intragenic sup pressor mutation. Am ₹ Hum Genet 1991;48:935-42.

11 Stone EM, Coppinger JM, Kardon RH, Donelson J. Ma III positively detects the mitochondrial mutation associated with type I Leber's hereditary optic neuropathy. Arch Ophthalmol 1990;108: 1417-20.

12 Huoponen K, Vilkki J, Aula P, Nikoskelainen EK, Savontaus $M$. A new mtDNA mutation associated with Leber hereditary optic neuroretinopathy. $\mathrm{Am} f \mathrm{Hum}$ Genet 1991;48:1147-53.
13 Leonardi A, Arata L, Farinelli M, et al. Cerebrospinal fluid and neuropathological study in Devic's syndrome. $f$ and neurol Sci 1987;82:281-90.

14 Leys D, Petit H, Block AM, Docx B, Basin B, Hache JC. Devic's optic neuromyelitis. 4 cases. Rev Neurol 1987; 143:722-8

15 O'Riordan JJ, Gallagher HL, Thompson AJ, et al. Clinical, CSF, and MRI findings in Devic's neuromyelitis optica. $\mathcal{f}$ Neurol Neurosurg Psychiatry 1996;60:382-7.

16 Silber MH, Willcox PA, Bowen RM, Unger A. Neuromyelitis optica (Devic's syndrome) and pulmonary tuberculosis. Neurology 1990;40:934-8.

17 Lefkowitz D, Angelo JN. Neuromyelitis optica with unusual vascular changes. Arch Neurol 1984;41:1103-5.

18 Fo FJ, Chiang $\mathrm{CH}$, Jong $\mathrm{YH}$, Chang $\mathrm{CH}$. Neuromyelitis optica (Devic's disease): report of one case. Acta Paedratrica Sinica 1995;30:428-31.

19 Hammans SR, Sweeney MG, Brockington M, MorganHughes JA, Harding AE. Mitochondrial encephalHughes JA, Harding AE. Mitochondrial encephalopathies: molecular genetic diagn

20 Wallace DC. Mitochondrial DNA sequence variation in human evolution and disease. Proc Natl Acad Sci USA 1994;91:8739-46.

21 Howell N, Kubacka I, Halvorson S, Howell B, McCullough DA, Mackey D. Phylogenetic analysis of the mitochondrial genomes from Leber hereditary optic neuropathy pedigrees. Genetics 1995;140:285-302.

22 Kalman B, Lublin FD, Alder $H$. Mitochondrial DNA mutations in multiple sclerosis. Multiple Sclerosis 1995; $1: 32-6$ 